\title{
COUMARINS: A UNIQUE SCAFFOLD WITH VERSATILE BIOLOGICAL BEHAVIOR
}

\author{
MANDEEP KUMAR GUPTA ${ }^{1 *}$, SUSHIL KUMAR ${ }^{2}$, SACHIN CHAUDHARY ${ }^{3}$
}

${ }^{1}$ Moradabad Educational Trust Group of Institutions, Faculty of Pharmacy, Moradabad, Uttar Pradesh, India. ${ }^{2}$ Department of Pharmaceutical Chemistry, School of Pharmaceutical Sciences, IFTM University, Moradabad, Uttar Pradesh, India. ${ }^{3}$ Department of Medicinal Chemistry, College of Pharmacy, University of Sharjah, Sharjah, United Arab Emirates. Email: mandeepkrgupta@gmail.com

\author{
Received: 06 November 2018, Revised and Accepted: 05 December 2018
}

ABSTRACT

Benzopyrones are the club of compounds that can be coumarins or flavonoids. The hydroxyl derivatives of coumarins such as 4-hydroxycoumarins and 7-hydroxycoumarins have extensive biological activities which have employed for the synthesis of miscellaneous coumarin derivatives. These derivatives have exhibited impressive pharmacological and physiological activities such as anticoagulant, antibacterial, antiviral, antitumor, bactericidal, fungicidal, anti-inflammatory agents, and anti-HIV activity. This review comprised pharmacokinetic studies, including absorption, distribution, and metabolism of coumarin analogs along with toxicological studies. The studies of coumarins and their derivatives exhibiting immense pharmacological activity are also summarized in the current study.

Keywords: Benzopyrones, Coumarins, Anticoagulant, Antibacterial, Antiviral, Antitumor.

(c) 2019 The Authors. Published by Innovare Academic Sciences Pvt Ltd. This is an open access article under the CC BY license (http://creativecommons. org/licenses/by/4. 0/) DOI: http://dx.doi.org/10.22159/ajpcr.2019.v12i3.30635

\section{INTRODUCTION}

Multitudinous, diverse and novel chemical analogs with the splendid potential to be used as drug have been obtained from natural sources. However, designing and synthesizing a novel drug analog using combinatorial chemistry along with high-throughput screening is still a challenging task for scientists. The word coumarins symbolize to "coumarou," acknowledged as the Tonka bean (Dipteryx odorata wild, Fabaceae), from which coumarin itself was isolated in 1820 [1]. Coumarin is affiliated to benzopyrone, which consist of a benzene ring fused to a pyrone ring $[2,3]$. The benzopyrones can be sub-classified into the benzo- $\alpha$-pyrones to which the coumarins belong and the benzo- $\gamma$-pyrones to which the flavonoids belong [4-6] (Fig. 1).

\section{CATEGORIZATION OF COUMARINS}

Murray et al. [11] classified coumarins into four sub-classes as represented in Table 1.

\section{PHARMACOKINETICS PORTRAIT OF COUMARINS}

\section{Absorption and distribution}

Coumarin in humans, on oral administration is rapidly absorbed from the gastrointestinal tract and distributed throughout the body. Coumarin and 7-hydroxycoumarin both are less soluble in water (0.22 and $0.031 \%$, respectively) and it expressed of limited in vivo bioavailability. However, coumarin and 7-hydroxycoumarin have elevated partition coefficients in aqueous solution as 21.5 and $10.4 \%$, respectively, which is agreeable for the rapid absorption of compounds. It also conjugates the fact that being nonpolar in nature, it can cross lipid bilayers easily by passive diffusion [9-14].

Coumarin is metabolized by the liver in the first pass with only between $2 \%$ and $6 \%$, reaching the systemic circulation intact [9]. The low bioavailability of coumarin, in addition to its short half-life $(1.02 \mathrm{~h}$ peroral vs. $0.8 \mathrm{~h}$ intravenous) has brought into question its importance in vivo and it is now acknowledged that coumarin is a prodrug, with 7-hydroxycoumarin being the compound of main therapeutic importance [8]. Ritschel et al. [15] proclaimed that 35\% of coumarin and $47 \%$ of 7 -hydroxycoumarin binds to plasma proteins. Therefore, the bioavailability of the compounds should not be problematic since the proportions that bound were well below the accepted critical value of $80 \%$ binding. The pharmacokinetics profiles of coumarin have been studied in rats, dogs, gerbils, rhesus monkeys, and humans [9]. Recently, numerous immunoanalytical approaches including enzyme-linked immunosorbent assay-based methods have been employed for the detection of coumarin and 7-hydroxycoumarin in urine [16]. Antibodybased biosensors have also been utilized with either electrochemistry or surface plasmon resonance (BIAcore) to detect coumarin analogs in many matrices $[17,18]$.

\section{Metabolism}

Multiple pharmacologists have accomplished their research in studying the metabolic fate of coumarins $[9,19,20]$. This study is essential to understand the possible coumarin-induced toxicity on metabolism [14]. Initially, coumarin is metabolized by cytochrome (CYP) P450-linked mono-oxygenase enzyme (CYP2A6) system in liver microsomes, leading to hydroxylation to form 7-hydroxycoumarin. Thereafter, phase II conjugation reaction resulting in a glucuronide conjugation is associated with 7-hydroxycoumarin. The 7-hydroxylase activity is remarkably high in human liver microsomes compared with its activity in the livers of other mammals. The activity of coumarin 3-hydroxylase is high in rodent microsomes but is absent in human microsomes.

It is noteworthy that coumarin can be metabolized by hydroxylation at all six possible positions around the carbons. However, metabolic product in the form of 7-hydroxycoumarin has attained recognition since it is produced in humans and can be easily analyzed. The hydroxylation at carbon three results in further metabolism through ring opening, yielding two more products, $o$-hydroxyphenyllactic acid and $o$-hydroxyphenylacetic acid $[9,14,21]$.

It is imperative to mention that genetic and environmental factors result in changing the expression of CYP2A6 between humans, which causes interindividual variations in the metabolism of coumarins [21]. Metabolic studies in humans include the administration of drugs orally followed by urine collection and analysis with or without timed fractionation $[7,22]$. The measurement of urinary 7 -hydroxycoumarin following an oral dose of coumarin is a vital biomarker of human hepatic CYP2A6, the CYP P- 450 isoform, which is responsible for the generation of 7-hydroxycoumarin in liver [14]. It is noticeable to mention that some 
Table 1: Classification of coumarins

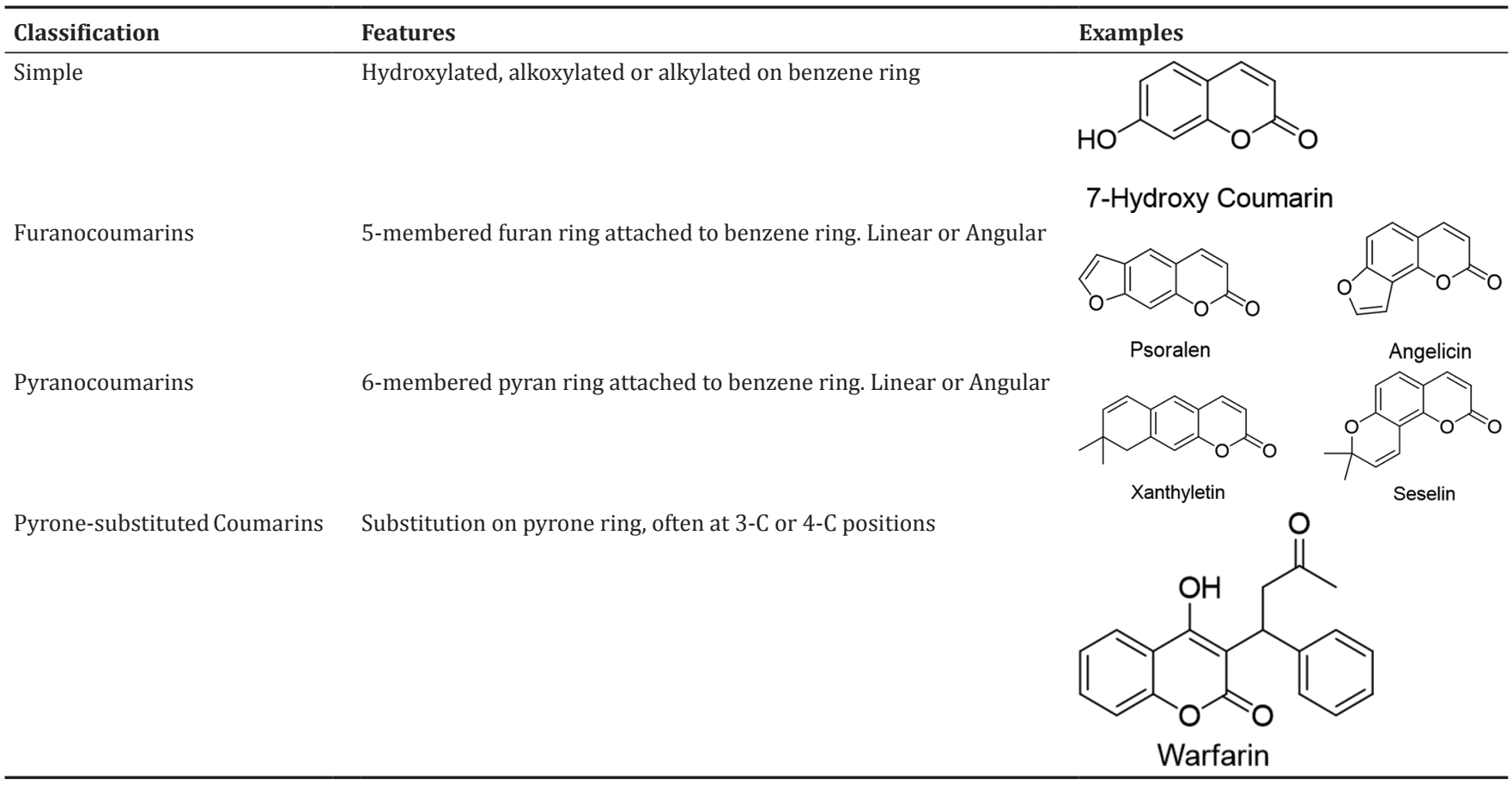

Table 2: Extent of coumarin metabolism to 7-hydroxycoumarin in various species

\begin{tabular}{llll}
\hline Species & Dose $(\mathbf{m g} / \mathbf{k g})$ & Collection time (h) & Urinary 7-HC (\% of Dose) \\
\hline Rat & 100, oral & 890 or 120 & 0.4 \\
Mouse & 21 , i.p. & 22 & 25 \\
Syrian hamster & 200, oral & 24 & 5 \\
Squirrel monkey & 200 , oral & 24 & 1 \\
Baboon & 200, oral & 24 & 60 \\
Human & $200 \mathrm{mg} /$ subject, oral & 24 & b79 (range 68-92) \\
& $200 \mathrm{mg} /$ subject, oral & 24 & (range 40-97) \\
\hline
\end{tabular}

${ }^{b}$ Shilling et al. [19], 'Egan et al. [7]

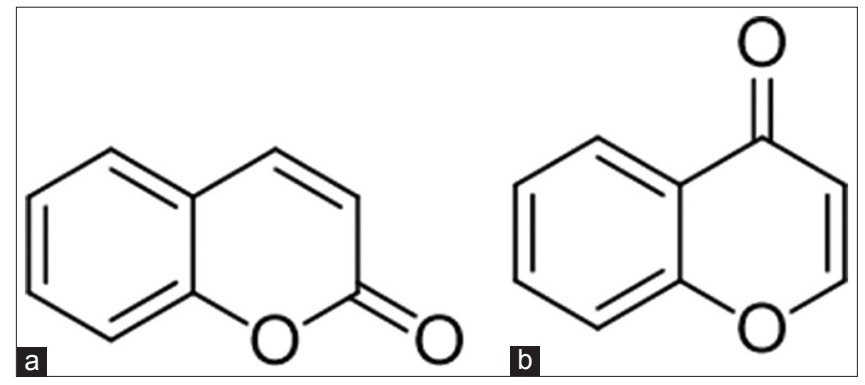

Fig. 1: The chemical structures of benzopyrone subclasses (benzo- $\alpha$-pyrone) [a], and (benzo- $\gamma$-pyrone) [b]

humans metabolize a significant proportion of coumarins in their body through 3,4-epoxidation pathway. CYP2A subfamily in humans has three genes, of which CYP2A6 is essential as the other two, namely CYP2A7 and CYP2A13 are either inactive or sometimes expressed improperly in the liver. CYP2A6 codes the enzyme, catalyzing the generation of 7-hydroxycoumarin (about 10\% of total P450) [26]. Recently, CYP2A6 has been reported to be polymorphically expressed in the human liver and involved in the metabolism of nicotine and cotinine. Hence, the various studies proclaimed that some drugs, including various coumarin analogs are metabolized chiefly by CYP2A6. Many substrates and inhibitors currently known to be metabolized by or interfered with CYP2A6 in vitro and in vivo have been illustrated by Pelkonen et al. [26,27]. Nowadays, spectrofluorometry, high-performance liquid chromatography and capillary electrophoresis are employed for the analysis of many metabolic products [23-25]. Recent in vitro studies include tissue slices, hepatocytes, subcellular fractions, and purified, and cDNA-expressed enzymes [9]. The data for various coumarin dose levels and collection periods are tabulated in Table 2.

\section{Toxicological studies}

Since 1954, the Food and Drug Administration classified coumarins as toxic due to its possibility to produce liver tumor in rats [28] and banned foods containing coumarin [12]. National Institute for Occupational Safety and Health referred coumarins as a carcinogenic agent. However, caution must be taken in extrapolating this information to human situations. Various other tests (Ames, micronucleus) have reported that coumarin and its metabolites are non-mutagenic [6]. Preliminary examinations of early studies showed that coumarin was a toxin, but the fact that rat is a poor model compared to humans in metabolism [28,29]. Since now, multiple studies have been accomplished to understand the acute, chronic and carcinogenic effects of coumarin in the rat and mouse. In these studies, hepatic biochemical and morphological changes in rats have been analyzed for various periods of coumarin administration (1 week-2 years). Depending on the dose administered, coumarin treatment results in an increase in relative weight and changes in various hepatic biochemical parameters. Single oral doses of coumarin have been shown to produce liver necrosis and increase plasma transaminase activities in DBA/2 strain mice [9]. In contrast, studies involving baboons, Syrian hamsters and certain mice strains were resistant to acute coumarin-induced hepatotoxicity. Species differences in coumarin-induced toxicity in vitro have been analyzed in cultured 


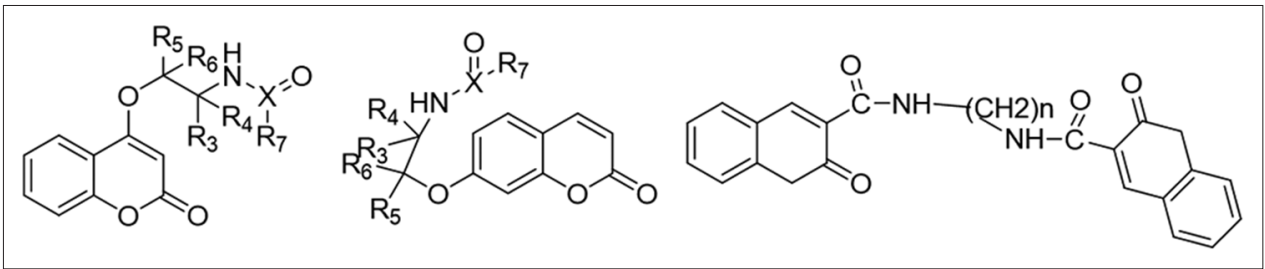

Fig. 2: List of 4-hydroxy and 7-hydroxy coumarin derivatives synthesized by treating with activated aziridines<smiles>COc1ccc(C(CCO)CCc2ccccc2)c(O)c1</smiles>

Fig. 3: A series of novel 1,2,4-triazole (compounds 3-6), 4,5-dicyanoimidazole (compound 7) and Purine (compound 8-13) coumarin derivatives and their acyclic nucleoside analogs 14-18

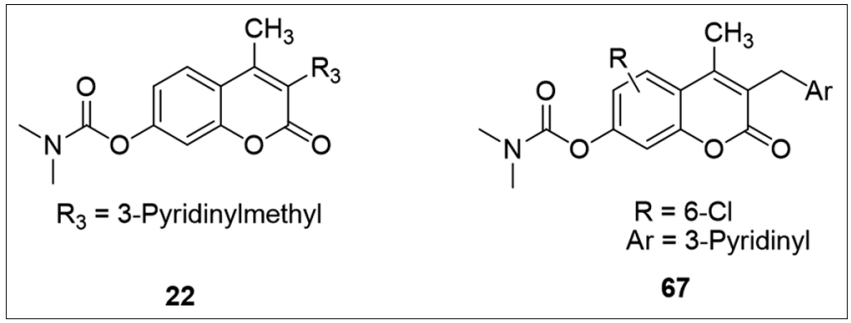

Fig. 4: The structure of compound 22 and 67 exhibited potent inhibitory activity against tumor necrosis factor- $\alpha$ production

hepatocytes. These studies provide evidence for species differences in coumarin-induced toxicity in vitro. The relative resistance of human and cynomolgus monkey liver slices and/or hepatocytes to coumarin toxicity correlates with coumarin 7-hydroxylation, the major pathway of coumarin metabolism in these species, being a detoxification pathway of coumarin metabolism. However, while coumarin-7-hydroxylation pathway is a detoxification pathway this does not appear to be the only reason for the resistance of a species to coumarin-induced toxicity. This may result in enterohepatic circulation enhancing the exposure of liver cells to toxic coumarin metabolites. Species such as Syrian hamster, baboon, and humans excrete coumarin metabolites primarily in the urine. Low level coumarin from diet and fragrances used in cosmetic products would not be estimated to produce any hepatotoxicity even in individuals with lack of 7-hydroxylase activity $[9,14]$.

\section{COUMARINS AS ACTIVE BIOLOGICAL AGENTS}

\section{Antibacterial activity}

Lin et al. [30] synthesized 4-hydroxy and 7-hydroxycoumarin derivatives by reaction with activated aziridines analog to produce a series of ring-opened products as represented in Fig. 2. 3-carboxy coumarin amide dimer derivatives were also synthesized by reacting aliphatic alkyl amines and alkyl diamines with benzotriazol-1yl-oxytripyrrolidinophosphonium hexafluorophosphate and $\mathrm{N}$, N-Diisopropylethylamine. Some of these compounds and dimer products exhibited antibacterial potential investigated by modified micro-plate antibiotic susceptibility test.

$\mathrm{Hu}$ et al. [31] synthesized imidazole bearing coumarin analogs in their structure and inspected for antibacterial activities against Escherichia coli, Staphylococcus aureus, Streptococcus agalactiae, and Flavobacterium cloumnare. The results revealed that compound 13 and 18 were excellent antimicrobial agents. However, compounds 9, 14, and 19 were potent against $S$. aureus, S. agalactiae, and F. cloumnare. The structure-activity relationship (SAR) study revealed that antibacterial efficacy was significantly affected by the length of linker and imidazole substituted group. Amin et al. [32] reported the synthesis of novel series of 7-hydroxy-4-methylcoumarin and 7-alkoxy-4-methylcoumarin derivatives following Pechmann condensation process. The derivatives were investigated for their antimicrobial activity against $S$. aureus, Bacillus subtilis, E. coli, Pseudomonas aeruginosa bacterial strains, and antifungal activity against Candida albicans. The author concluded that derivatives bearing 7-hydroxy group exhibited better antimicrobial activity than those bearing 7-alkoxy group in the structure. Aziem et al. [33] synthesized 2,3-diyhdro-1,3,4-thiadiazoles, pyrazoles, and coumarin containing benzofuran derivatives following the approach of green chemistry and investigated for their antibacterial activity. Hamid and Kubba [34] reported the synthesis and antibacterial activity of Schiff bases, chalcones, hydrazones, and hydrazinyl thiazoles derivatives incorporated in 8-formyl-7-hydroxy-4-methyl coumarin derivatives. The results revealed that novel chalcones having a phenyl group in the structure represented excellent activity against Gram-negative bacterial strains. However, hydrazone and cyclized hydrazinyl thiazole derivatives exhibited good activity against Gram-positive bacterial strains.

\section{Antitubercular activity}

Tandon et al. [35] explored the anti-tuberculosis (TB) potential of a series of amino and acyl aminocoumarins against H37Rv strain. The analogs were also tested for their MBCs, fractional inhibitory concentration index values, and cytotoxicity. The minimal inhibitory concentrations (MICs) for a susceptible and a multidrug-resistant clinical isolate of Mycobacterium tuberculosis were also evaluated. Electron and fluorescence microscopy of the test compound-treated mycobacterial samples was also analyzed to find out the target site. 7-Amino-4-methylcoumarin (7-amino-4-methyl-2H-chromen-2-one; NA5) showed the lowest MIC of $1 \mathrm{mg} / \mathrm{L}$ against H37Rv strain. Reddy et al. [36] synthesized a series of coumarin-oxime ether using the $\mathrm{SN}_{2}$ reaction of bromomethyl coumarins with butane-2,3-dione monoxime and the derivatives were tested for in vitro anti-TB activity against $\mathrm{MTBH}_{37} \mathrm{Rv}$ strain. The compound (1 h) was found to be the most active by exhibiting MIC of $0.04 \mu \mathrm{g} / \mathrm{ml}$ which is closer to the MIC value of standard drug isoniazid $(0.02 \mu \mathrm{g} / \mathrm{ml})$. The compound $(1 \mathrm{~h})$ was further used to explore the mode of interaction with a model serum protein, bovine serum albumin which displayed excellent interaction without influencing its normal functioning. Mangasuli et al. [37] synthesized a series of substituted C-4 bridged coumarin-theophylline hybrids and assayed for their anti-TB activity against M. tuberculosis $\mathrm{H}_{37} \mathrm{Rv}$, antimicrobial activity against Gram-positive bacteria (S. aureus) and Gram-negative bacterial strains (E. coli, Salmonella typhi) as well as fungal strain (C. albicans). The compound (3a) represented remarkable 


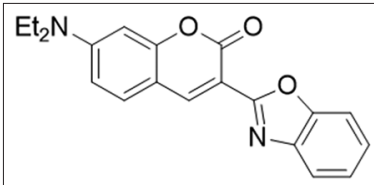

9<smiles>CCN(CC)c1ccc2c(C#N)c(-c3nc4ccccc4o3)c(=O)oc2c1</smiles>

10

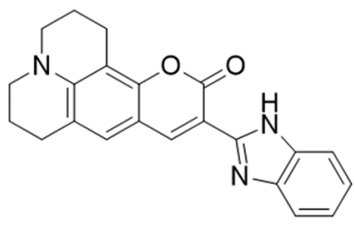<smiles>CCN(CC)c1ccc2cc(-c3nc4ccccc4s3)c(=O)oc2c1</smiles>

12

15

Fig. 5: The structure of 7-diethylaminocoumarin derivatives

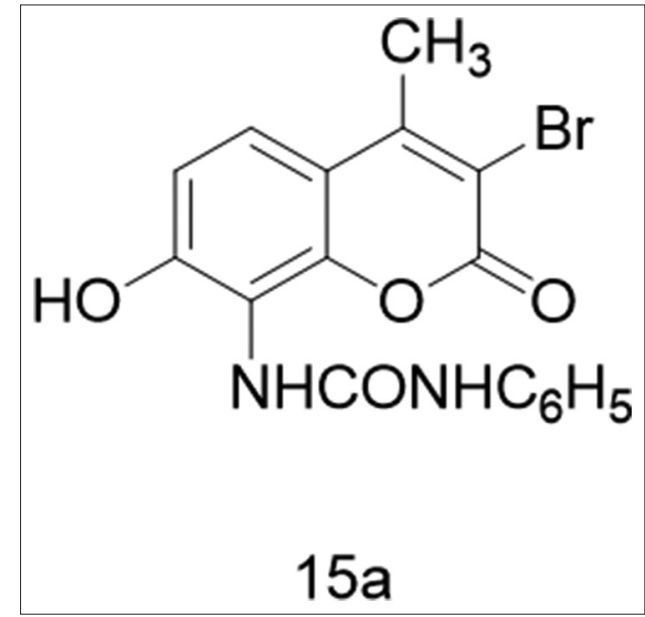

Fig. 6: The structure of most active compound (15a) from novel 3-bromo-4-methyl-7-methoxy-8-amino substituted coumarins, benzoxazoles, and/or benzoxazine-8-ones

anti-TB activity with MIC of $0.12 \mu \mathrm{g} / \mathrm{ml}$. Compounds (3a, 3f) exhibited significant anti-microbial activity and $3 \mathrm{a}, 3 \mathrm{~b}$, and $3 \mathrm{f}$ revealed moderate antifungal activity. The structural analysis of synthesized compounds was accomplished using crystal X-ray diffraction technique, and molecular docking study against 4DQU enzyme of $M$. tuberculosis exhibited remarkable binding interactions.

\section{Anticancer activity}

Benci et al. [38] synthesized and investigated antitumoral potential of derivatives of novel 1,2,4-triazole (compounds 3-6), 4,5-dicyanoimidazole (Compound 7) and purine (compound 8-13) coumarin derivatives and their acyclic nucleoside analogs (14-18) (Fig. 3). The results of antitumoral assays conducted on human tumor cell lines, communicated that compound 6 had moderate antiproliferative activity against the HeLa cell line $\left(\mathrm{IC}_{50}: 35 \mu \mathrm{M}\right)$, whereas compound 10 was moderately active against the HeLa $\left(\mathrm{IC}_{50}: 33 \mu \mathrm{M}\right)$, HepG2 $\left(\mathrm{IC}_{50}: 25 \mu \mathrm{M}\right)$, and SW620 $\left(\mathrm{IC}_{50}: 35 \mu \mathrm{M}\right)$ cell lines.

Cheng et al. [39] synthesized and explained SAR of various coumarin derivatives exhibiting tumor necrosis factor (TNF)- $\alpha$ inhibitory action. The compound 22 and 67 (Fig. 4) exhibited excellent TNF- $\alpha$ inhibitory action in human peripheral blood mononuclear cells triggered by bacterial lipopolysaccharide (LPS).

Lee et al. [40] synthesized a series of 7-diethylaminocoumarin derivatives and investigated for anti-proliferative action against human umbilical vein endothelial cell (HUVEC) and some other cancer cells. This research concluded that the cyano group at position- 4 will elevate the biological efficacy. In particular, compounds 9 and 10 represented remarkable anti-proliferative activity against various cancer cell lines, and compounds 12 and 15 displayed commendable selectivity for HUVEC (Fig. 5). Hence, these analogs can be utilized as a prototype to develop novel non-toxic angiogenesis inhibitors and small molecular ligands to target HUVEC.

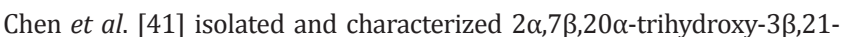
dimethoxy-5-pregnene(1),6,7,9 $\alpha$-trihydroxy-3,8,11 $\alpha$-trimethylcyclohexo[d, e]-coumarin (2), 3ß-hydroxy-27-benzoyloxylup-20(29)-en-28-oic acid (3), and 3ß-hydroxy-27-benzoyloxylup-20 (29)-en-28-oic acid methyl ester (4), along with 24 known compounds from the roots and aerial parts of Helicteres angustifolia (Sterculiaceae). The two-cucurbitacin derivatives, cucurbitacin $\mathrm{D}$ and J exhibited excellent anti-proliferative activities against hepatocellular carcinoma BEL-7402 cells and malignant melanoma SK-MEL-28 cells.

Nofal et al. [42] synthesized and investigated a series of novel 3-bromo4-methyl-7-methoxy-8-amino substituted coumarins and 2-substituted 7-bromo-6-methyl-8H-pyrano-benzimidazoles, benzoxazoles, and/ or benzoxazine-8-ones against their cytotoxic potential. Out of the synthesized derivatives, the compound 15a (Fig. 6) represented remarkable antitumor activity against Ehrlich ascites carcinoma.

Lou et al. [43] reported for a novel coumarin, Juglans side C isolated from the bark of Juglans mandshurica. Juglans side C exhibited reasonable cytotoxicity against human hepatocellular carcinoma Hep3B cells $\left(\mathrm{IC}_{50}\right.$ value: $\left.70.9 \mu \mathrm{M}\right)$. In addition, Annexin V-FITC/PI staining assay technique specified that significantly induced apoptosis in Hep3B cells. The study concluded that this plant could be an auspicious plant for the treatment of HCC and its findings could be explored in future research.

Tan et al. [44] synthesized and investigated a series of 8-ethoxy-3nitro-2H-chromene based HDACIs against K562, A549, MCF-7, PC3, and HeLa cancer cell lines. The research revealed that o-amino anilide and D-Phe substituted $\alpha$-amino amide derivatives (16a and 16b) were more effective toward HADC1 over HADC2 and were moderated to weak active over HADC6. However, the amide ZBG analogs (12a and $12 \mathrm{~b}, 14$ and 15) were only average HDAC6 inhibitors and were more active over HDAC1 and HDAC2. The o-aminoanilides 9b, 9c, 10b, 10c, $11 \mathrm{~b}$, and $\alpha$-aminoamides, $16 \mathrm{a}$ and $16 \mathrm{~b}$ were effective against HADC1. The phenyl substituted o-aminoanilides $10 \mathrm{~b}$ and $10 \mathrm{c}$ were more active than MS-275 as HADC1 inhibitors and more selective toward HADC2. Lv et al. [45] designed and synthesized a series of 2-phenylpyrimidine derived coumarin analogs bearing telomerase-inhibiting activity. These analogs were investigated for cytotoxic action against CNE2, $\mathrm{KB}$, and Cal27 cancer cell lines. The results displayed that most of the 
compounds were effective in resisting tumor cell proliferation and concluded that compound 13 is a highly potent derivative that can inhibit CNE2 proliferation. The molecular docking studies revealed that compound 13 bonded through multiple interactions, including hydrogen bonding and hydrophobic interactions against telomerase reverse transcriptase. Yu et al. [46] designed and synthesized 34 new dihydroartemisinin-coumarin analogs, and these analogs represented remarkable cytotoxic activities against HT-29 and MDA-MB-231 cell lines, especially under hypoxia condition. The SAR study and docking analysis had shown that carbonic anhydrases IX was the main target of the hybrids. The results had shown that these compounds noticeably exhibited antiproliferative activity against HT-29 cell lines, by arresting G0/G1 phase of HT-29 cells, blocked the movement of tumor cells, and induced a great reduction in mitochondrial membrane potential. Batran and Kassem et al. [47] reported the synthesis of a novel series of 4-phenylcoumarin derivatives, and explored these compounds for anticancer activity against MCF-7 cell lines. Compounds $3 \mathrm{a}, 3 \mathrm{~b}$, and $3 \mathrm{f}$ represented the excellent cytotoxic effect on MCF-7 cell lines without producing any cytotoxic effect on human normal skin cell line (BJ-1). In addition, tubulin polymerization assay was also accomplished for the most potent compounds, i.e. $3 \mathrm{a}, 3 \mathrm{~b}$, and $3 \mathrm{f}$. The results revealed that the three derivatives represented significant inhibitory activity of TUBb polymerization in comparison with standard drug colchicine $\left(\mathrm{IC}_{50}=9.37,2.89\right.$ and $6.13 \mu \mathrm{M}$, respectively, vs. $6.93 \mu \mathrm{M}$ for colchicine). Compound 3a was further exposed to cellular mechanistic studies on MCF-7 cells and showed induction of apoptosis and cell cycle arrest at $\mathrm{G} 2 / \mathrm{M}$ phase, along with its significant activation of caspase-7. The combined studies of molecular docking, pharmacophore hypothesis, and MD studies exposed remarkably information on the structural features of the molecules, which are essential to explore drug interactions and designing of the novel drug molecule. Emami et al. [48] synthesized a new series of 3-(4-aminothiazole-5-carbonyl)2 Hchromen-2-ones, $(3 \mathrm{a}-1)$ and $(4 \mathrm{a}-\mathrm{c})$ with a cyclic amine, substituted cyclic amine, aniline or substituted aniline moieties, and investigated for cytotoxic potential employing MTT assay against MCF-7, HepG2, and SW400 cell lines. The thiomorpholine derivative (3k) was potent with ( $\mathrm{IC}_{50}$ values: $7.5-16.9 \mu \mathrm{g} / \mathrm{ml}$ ). The compound (3k), against MCF-7 cells represented apoptosis and ceased the cell proliferation at the G1-phase. The analogs had significant effects for free radical scavenging activity and ferric-reducing power as evaluated by 2,2-diphenylpicrylhydrazyl (DPPH) and ferric reducing antioxidant power assay method. Singh et al. [49] designed and synthesized 28 novel triazolebound isatincoumarin hybrids, and investigated for antiproliferative potential against human cancer cell lines of THP-1, COLO-205, HCT-116, and PC-3 and compounds A1 to A6, B1 to B4, and C1 to C3 had prodigious inhibitory action against THP-1, COLO-205, and HCT-116 cell lines. The SAR study expressed that the cytotoxic activity rely on substitution on isatin and the length of carbon-bridge linking isatin moiety with triazole moiety. Two carbon-bridge and unsubstituted isatin were found to be essential for cytotoxicity. Three most potent hybrids (A1, $\mathrm{A} 2$, andB1) were also evaluated for tubulin polymerization inhibition activity and compound (A1) was found to be most potent with $\mathrm{IC}_{50}$ value of $1.06 \mu \mathrm{M}$. Zhou et al. [50] designed and synthesized 5 new analogs of phenylsulfonylfuroxan joined with 3-benzyl coumarin and their seco-B-ring derivatives (2-6). The compound 3 was highly active anti-cancer agent with $\mathrm{IC}_{50}$ values ranging from $0.5 \mathrm{nM}$ to $143 \mathrm{nM}$ against 9 drug-sensitive and 4 drug-resistant cancer cell lines. Compound 3 induced the early apoptosis and hardly affected the cell cycle of A2780. Xiang et al. [51] rationally optimized a series of3-aryl-4aniline/aryloxy-2H-chromen-2-one derivatives using structure-based modification of leadcompound LE-18d to obtain a multifunctional effect against ER $\alpha$ and VEGFR-2. By means ofbioisosteric replacement, $\mathrm{F}$ atom was incorporated to C-4' position of 3-phenyl substituent while, 0 atom was substituted to the 4-position of coumarin moiety, for anticipated interactions with essential amino acid residues of targeted ER $\alpha$ receptor and VEGFR-2 enzyme. Among these derivatives, 0 -linked compounds represented potent ER- $\alpha$ binding affinities and antiproliferative potential against cancer cells and angiogenesisrelated cells. Further investigation exposed that (42d) was able to inhibit MCF-7 cell migration and arrest cell cycle at G0/G1 phase in MCF-7 cells in a concentration-dependent manner. Furthermore, a significant anti-estrogenic property observed in RT-PCR, and (42d), inhibited the activation of VEGFR-2 and the signaling transduction of Raf-1/MAPK/ERK pathway in MCF-7 cells. Molecular docking analysis of (42d) presented ER- $\alpha$ binding mode embodying three essential hydrogen-bonding interactions, which is the characteristic character of selective estrogen receptor modulator. Bu et al. [52] synthesized and characterized a chain of novel $5 \mathrm{a}, 8 \mathrm{a}$-epidioxyandrost-3b-ol-17(0-phenylacetamide) oxime derivatives (9a-o). These analogs were investigated for their anti-proliferative activities against human hepatocellular carcinoma cells (HepG2, Sk-Hep1) and human breast cancer cells (MCF-7, MDAMB231). The compounds 9d, 9f, 9h, 9j, and $9 \mathrm{~m}$ exhibited significant anti-proliferative activity with $\mathrm{IC}_{50}<20 \mu \mathrm{M}$ ). Moreover, coumarin-9d conjugate (12) localized in mitochondria, leading to higher anticancer activities over the lead moiety, which was confirmed by a fluorescence imaging technique.

\section{Antimicrobial activity}

Al-Haiza et al. [53] synthesized Pyrimidino [5`,4 -6,5]-pyridino[3`,2`$6,5]$-and pyrrolo[3 $, 2 `-5,6] 4 \mathrm{H}$-pyrano-[3,2-c][1] benzopyran-6-one derivatives (5-7 and 10 ) by reacting 2 -amino-4-( $p$-bromophenyl)-3cyano(carboethoxy)-4H,5H-pyrano[3,2-c][1] benzopyran-5-ones(3a,b) with a variety of reagents (Fig. 7). Alkylation of (3b) with either 2-furoyl chloride or chloroacetyl chloride produced $2-\mathrm{N}$-substituted derivatives (9a, b). Benzofurano [3,2-b] 4H-pyran derivative (12) was also prepared and investigated for antimicrobial activity.

López-Rojas et al. [54] synthesized a novel series of 26 compounds having coumarin-1,2,3-triazole conjugates with varied alkyl, phenyl, and heterocycle moieties at $\mathrm{C}-4$ of the triazole nucleus using a copper(I)-catalyzed, Huisgen 1,3-dipolar cycloaddition reaction. Out of these analogs 6 compounds exhibited remarkable antibacterial activity against Enterococcus faecalis (MIC: $12.5-50 \mu \mathrm{g} / \mathrm{ml}$ ) based on their MICs against a selected microorganism. Furthermore, these compounds represented comparatively minimal toxicity against human erythrocytes. Tiwari et al. [55] synthesized 15 novels 3-((dicyclohexylamino) (substituted phenyl/heteryl)-methyl)-4hydroxy-2H-chromen-2-onederivatives (4a-o) under solvent-free<smiles>CCOC(=O)C1C(=N)Oc2c(c(=O)oc3ccccc23)C1C(=O)OCC</smiles>

Fig. 7: The structure of 2-amino-4-( $p$-bromophenyl)-3cyano(carboethoxy)-4H,5H-pyrano[3,2-c][1]benzopyran-5-ones (3a,3b)

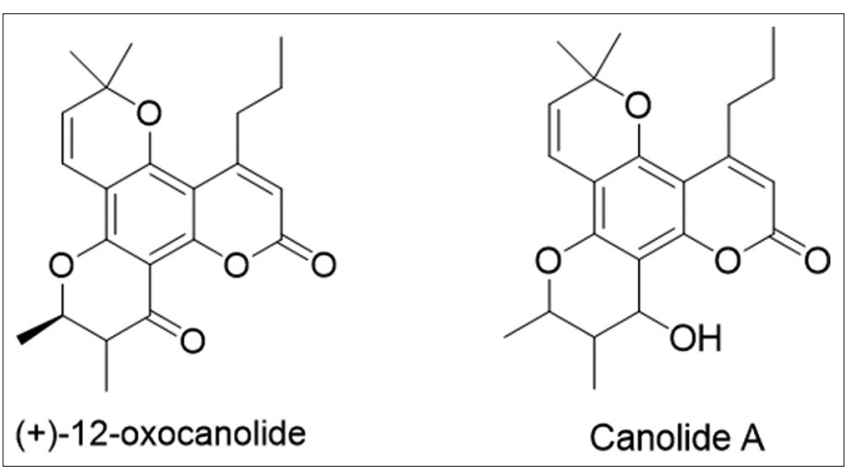

Fig. 8: The structure of (+)-12-oxocanolide and canolide A 


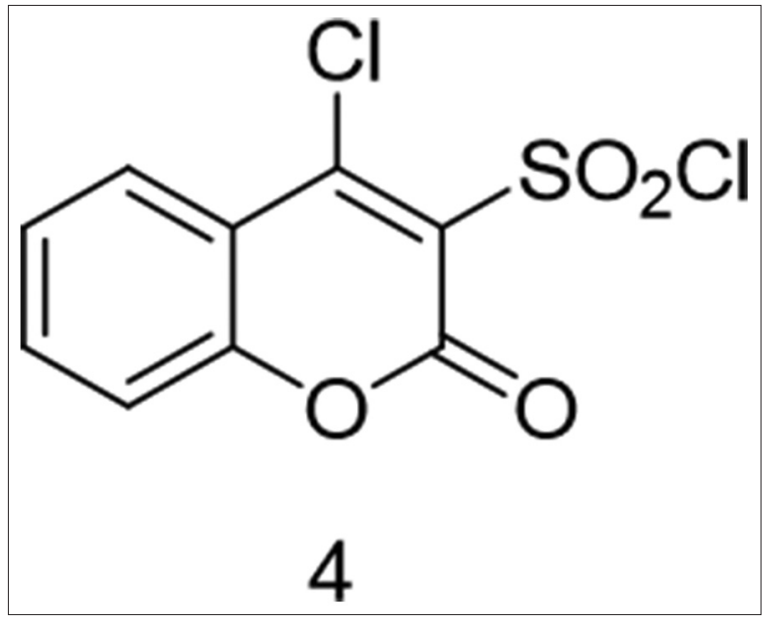

Fig. 9: The structure of 4-chlorocoumarin-3-sulfonyl chloride (4)<smiles>[X][X]C(=O)NC(=O)c1c(O)c2cc([R])ccc2oc1=O</smiles>

Fig. 10: The structure of novel coumarin-3-carboxamides and their hybrids with the alpha-lipoic acid

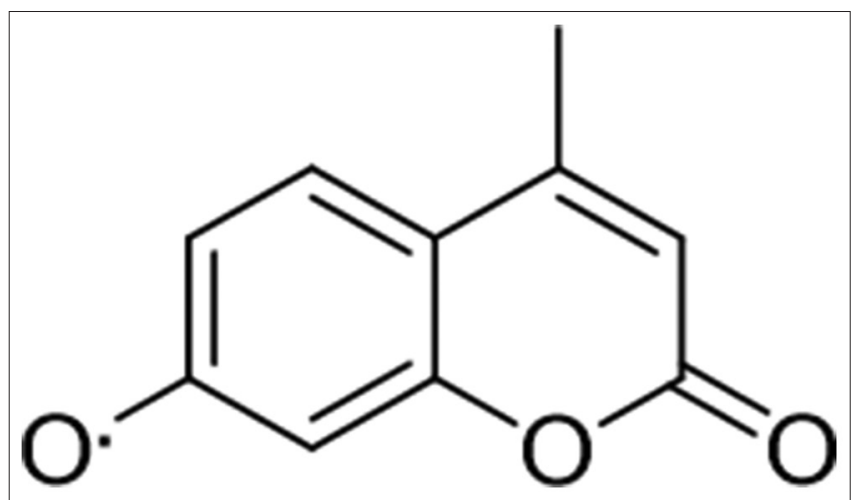

Fig. 11: The structure of 4-methyl-7-hydroxycoumarin

condition using the ionic liquid $\left[\mathrm{Et}_{3} \mathrm{NH}\right]\left[\mathrm{HSO}_{4}\right]$ as a catalyst which was further characterized by IR, ${ }^{1} \mathrm{H}-\mathrm{NMR},{ }^{13} \mathrm{C}-\mathrm{NMR}$, and mass spectral analysis. All the analogs were investigated for their antifungal and antibacterial efficacy, the results revealed that the compound (4k) was potent antifungal and the compound (4e) was potent antibacterial agent. The compound (4k) acts by inhibition of ergosterol biosynthesis in C. albicans that was confirmed using an ergosterol extraction and quantitation assay technique. The most active compounds $4 \mathrm{e}$ and $4 \mathrm{k}$ were non-cytotoxic against human cancer cell line HeLa.

\section{Anti-HIV activity}

Kostova et al. [56] presented the SAR of various synthetic coumarin derivatives used as an anti-HIV agent (Fig. 8). These were accomplished as reverse transcriptase inhibitors, protease inhibitor, and integrase inhibitors. Jashari et al. [57] developed an improved synthetic scheme in which 4-chlorocoumarin-3-sulfonyl chloride (4) was synthesized in excellent yield (Fig. 9). The synthesized compound 4-chlorocoumarin3 -sulfonyl chloride (4) was further reacted with 2-aminopyridines and 2-aminothiazoles to yield substituted pyrido and thiazino-1,2,4thiadiazino-benzopyranone dioxides (a potential anticancer and antiHIV agents).

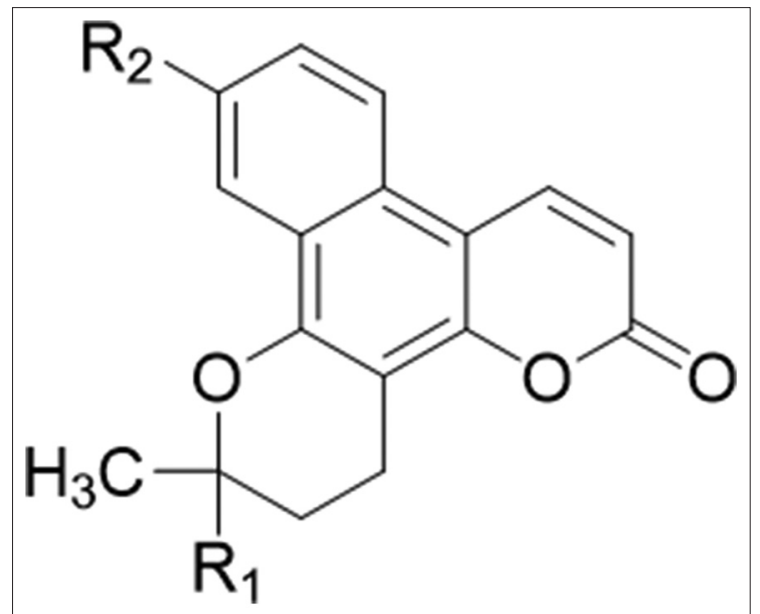

Fig. 12: The structure of 3 -hydroxy- $\beta$-lapachone 4 with ylide 5 gave the coumarin derivative $7 \mathrm{a}$

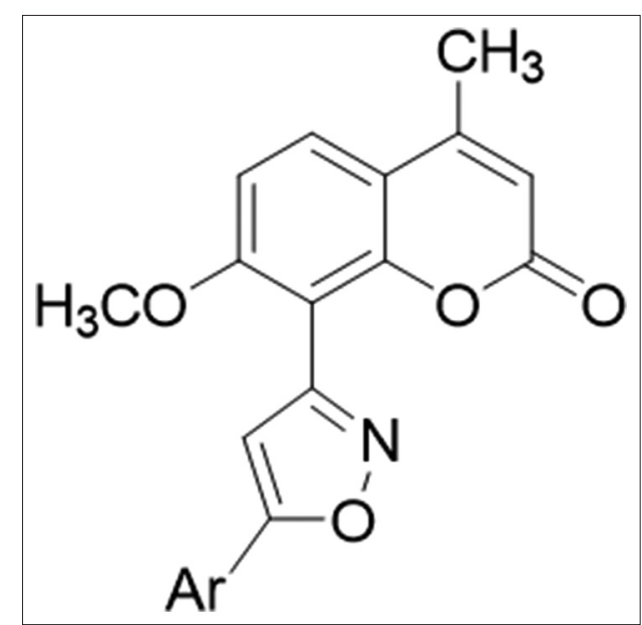

Fig. 13: The structure of the series of 7-methoxy-4-methyl-8-[5(substituted aryl) isoxazol-3-yl]-2H-benzopyran-2-ones<smiles>CN/N=C/c1ccc2ccc(=O)oc2c1</smiles>

Fig. 14: The structure of novel coumarin derivatives with a 7-azomethine linkage

\section{Antioxidant activity}

Majumdar et al. [58] evaluated in vitro antioxidant potential and inhibition of $\alpha$-amylase and $\alpha$-glucosidase activities of methanolic extracts of leaves of few Indian medicinal plants. The antioxidant activities of the samples were measured by two different methods while the Folin-Ciocalteu reagent assay was used to estimate the phenolic contents of extracts. Methanolic extracts from dried leaves of Phyllanthus emblica, Cajanus cajan, Cannabis indica, and Formica pratensis were prepared. DPPH radical scavenging and iron chelating methods estimated antioxidant activities. The inhibitions of carbohydrate-hydrolyzing key enzymes, for example, $\alpha$-amylase and $\alpha$-glucosidase activities were assayed. Acarbose was used as a reference compound in both of assay procedures. Goudgaon et al. [59] developed that the reaction of synthon 3-acetyl-2H-chromen-2-one (1) with 3-substituted aryl-1-phenylpyrazol carboxaldehyde (2a-d) gave intermediate compounds 3-[3-(3-substituted aryl-1-phenylpyrazol-4- 
yl)acryloyl]-2H-chromen-2-ones (3a-d). These chalcones on cyclization with thiourea produced desired target compounds (4a-d). These compounds were investigated for their antimicrobial and antioxidant activities. Melagraki et al. [60] designed and synthesized a series of novel coumarin-3-carboxamides and their hybrids with the alpha-lipoic acid. The synthesized compounds were evaluated for their antioxidant activity to inhibit in vitro lipoxygenase and in vivo anti-inflammatory activity (Fig. 10).

Singh et al. [61] studied and described the kinetics and the transient absorption spectra from the reactions of ${ }^{\bullet} \mathrm{OH}, \mathrm{O}^{*-}, \mathrm{e}^{-}{ }_{\mathrm{aq}}$, and $\mathrm{SO} 4^{-{ }^{-}}$radicals with coumarin, 4-methyl-7-hydroxycoumarin, 7-methoxycoumarin, and 6,7-dimethoxycoumarin in aqueous solutions by pulse radiolysis with optical detection (Fig. 11)

Beillerot et al. [62] synthesized and evaluated the protective effects of coumarin derivatives against oxidative stress induced by doxorubicin (DOX). 4-Methyl-7,8-dihydroxycoumarin represented excellent antioxidant potential, less cytotoxicity and could decrease reactive oxygen species (ROS) production generated by DOX without affecting DOX toxicity in MCF7 cells.

\section{Anti-inflammatory activity}

Nicolaides et al. [63] synthesized 3-hydroxy- $\beta$-lapachone (4) with ylide (5) gave the coumarin derivative (7a), which was transformed to compounds (10-14). Compound 14 was then converted to benzo[f] seselin (15) as well as to benzo[1] khel lactones 16, 18 from which the targeted compounds 17, 19I, 19II, 20, 21I, and 21II were synthesized (Fig. 12). All the compounds were interacted with DPPH in a concentration and time-dependent manner. All the compounds were highly active against the soybean lipoxygenase, whereas compounds 12,17 , and 19II significantly compete with dimethylsulfoxide (DMSO) for $\bullet \mathrm{OH}$. Compounds $7 \mathrm{a}, 7 \mathrm{~b}, 12$, and 17 showed $48.7-58.9 \%$ antiinflammatory activity against carrageenin-induced rat paw edema.

Sreeja et al. [64] reported the in silico molecular modifications of proposed derivatives using different software. The five analogs were shortlisted for the synthesis with the help of selection parameters

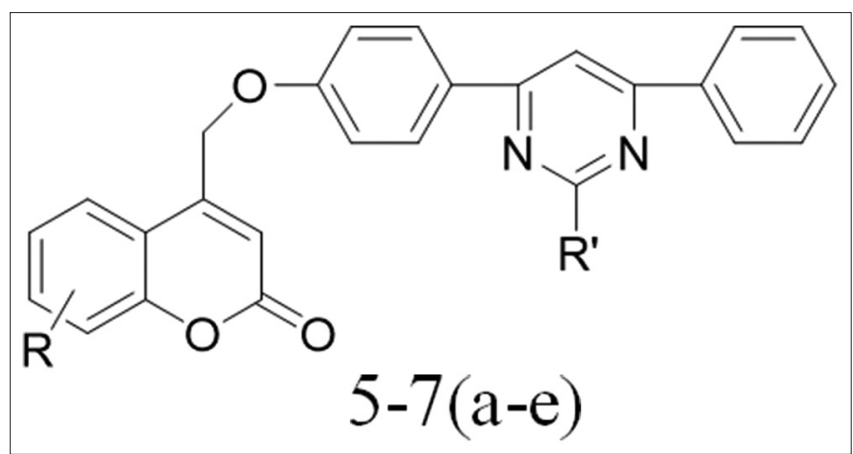

Fig. 15: The structure of novel series of 4-[4-(6-phenyl-pyrimidin 4-yl)-phenoxymethyl]-chromen-2-ones [5-7(a-e)] from various 4-bromomethyl coumarins 1(a-e) and were synthesized by conventional and microwave assisted synthetic methods. The synthesized compounds were subjected to pharmacological screening such as acute toxicity study, analgesic activity, and anti-inflammatory activity by carrageenan-induced rat paw edema method. Gummudavelly et al. [65] synthesized a new series of 7-methoxy-4-methyl-8-[5-(substituted aryl)isoxazol-3-yl]-2Hbenzopyran-2-ones by cyclization of chalcones, 8-(2-substituted prop-2ene)-7-methoxy-4-methyl-2H-benzopyran-2-ones with hydroxylamine hydrochloride (Fig. 13). The synthesized compounds were investigated for their antimicrobial and anti-inflammatory activities and some of them exhibited significant activity.

Nicolaides et al. [66] synthesized a series of novel coumarin derivatives with a 7-azomethine linkage starting from 7-formylcoumarin (Fig. 14). The compounds were tested in vivo for their anti-inflammatory and in vitro for antioxidant potential. Compounds (3a) and (3e) displayed significant anti-inflammatory action against carrageenan-induced rat paw edema.

Chen et al. [67] designed and synthesized a series of new phenylpyrazoline-coumarin derivatives $(4 a-4 m)$. All of the compounds had been assayed for their anti-inflammatory activity using carrageenaninduced paw edema technique for evaluating their inhibition against LPS-induced IL-6 release. The compound (4m) was potent antiinflammatory agent resulted in inhibiting IL-6, TNF- $\alpha$, and nitric oxide (NO) production. In addition, the compound (4m) significantly suppressed the expressions of nitric oxide synthase, cyclooxygenase-2 and the productions of IL-6, TNF- $\alpha$, NO through NF-кB/MAPK signaling pathway. Moreover, in vivo studies revealed that compound $(4 \mathrm{~m})$ could inhibit AA-induced rat ankle joints. Yong Jiang et al. [68] isolated three new prenylated phenylpropenols, exotiacetals A-C (1-3), 10 new coumarin derivatives, exotimarins A-I (4-13), and 35 known analogs (14-48) from the roots of Murraya exotica. The absolute configurations of the new compounds were characterized through comparison of their specific rotations, single-crystal X-ray diffraction data, Mosher's method, the ECD exciton coupling method, comparison of experimental and calculated ECD data, and the ECD data of the in situ formed transition metal complexes. Compounds 1-3 were biosynthesized from two prenylated p-coumaryl alcohol moieties through Diels-Alder [4+2] cycloaddition and cyclic hemiacetal formation reactions creating a unique hexahydro-1H-isochromen-1-ol system. Compounds1, 28, 33, and 35 demonstrated inhibition against LPS-induced NO production in BV-2 microglial cells with IC $_{50}$ values of $8.6 \pm 0.3,11.8 \pm 0.9,15.5 \pm 0.9$, and $16.9 \pm 1.0 \mu \mathrm{M}$, respectively.

\section{Antipyretic activity and analgesic activity}

Keri et al. [69] synthesized a series of 4-[4-(6-phenyl-pyrimidin4-yl)-phenoxymethyl]-chromen-2-ones [5-7(a-e)] from various 4-bromomethyl coumarins 1(a-e) (Fig. 15). The synthesized compounds were screened for analgesic and antipyretic activities at a dose of 25 and $100 \mathrm{mg} / \mathrm{kg}$, body weight, respectively. The compounds 5 (d), 6 (c), and 7 (d) represented significant analgesic activity comparable with standard drug Analgin using Tail-flick model. Compounds 5 (a) and 7 (a-d) exhibited significant anti-pyretic activities comparable with standard drug aspirin using yeast induced pyrexia model. QSAR

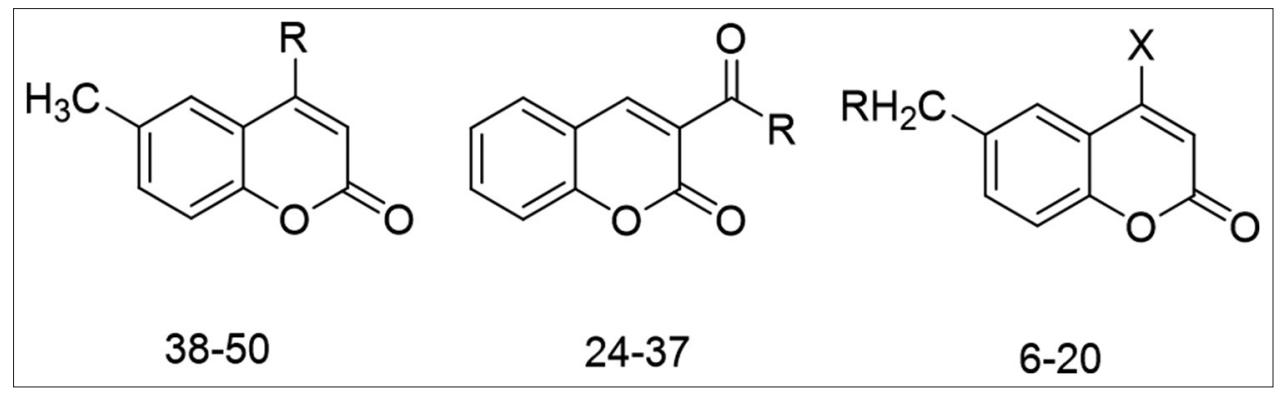

Fig. 16: The structure of coumarin analogs with phenylpiperazine 


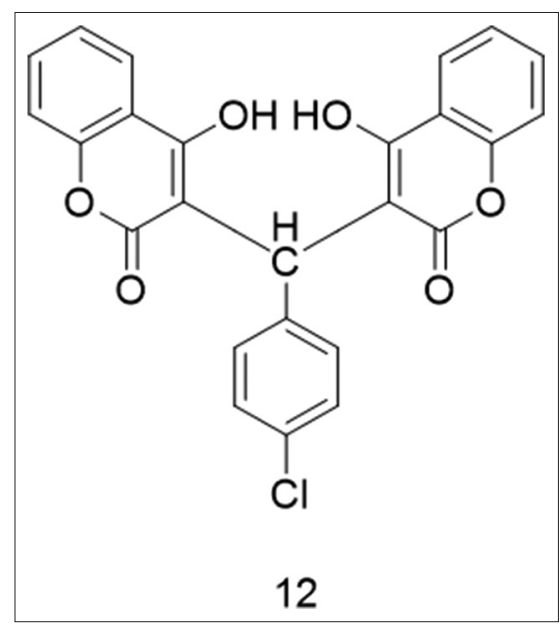

Fig. 17: The structure of 3,3'-(4-chlorCophenylmethylene)bi s-(4-hydroxy-2H-1-benzopyran-2-one) (12)

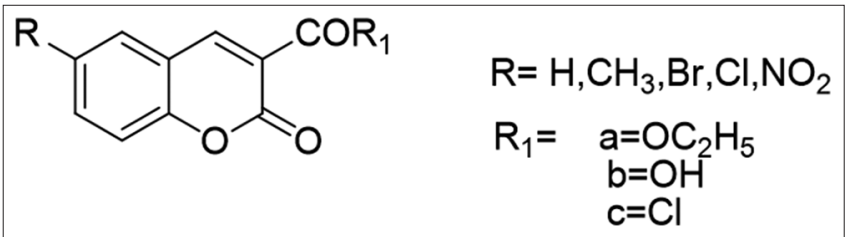

Fig. 18: The structure of the series of coumarin-3-acyl derivatives

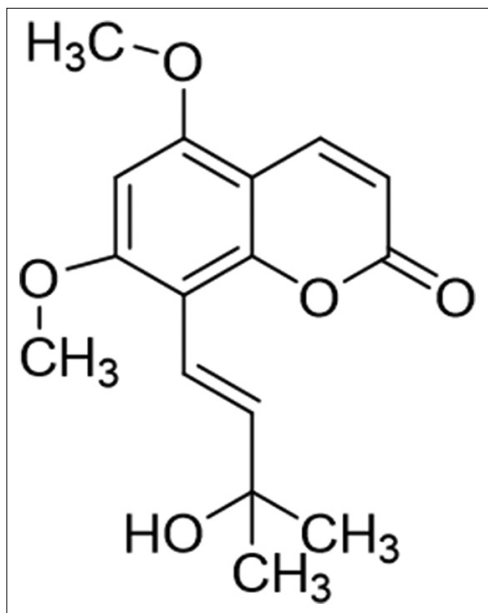

Fig. 19: The structure of 5,7-dimethoxy-8-(3'-hydroxy3'methyl-1'-butene)-coumarin

studies concluded that compounds with 2-amino group of pyrimidine ring increase analgesic and antipyretic activities and compounds with 2-hydroxyl and 2-thio group of the pyrimidine ring improves DNA cleavage activities.

\section{Anti-Alzheimer's activity}

Zhou et al. [70] designed and synthesized three series (A-C) of coumarin analogs by substitution with phenylpiperazine and investigated against Alzheimer's disease (AD) (Fig. 16). The anticholinesterase activities of these compounds were also evaluated according to Ellman's method against freshly prepared acetylcholinesterase (AChE) using donepezil as the standard drug.

Costas-Lago et al. [71] synthesized a series of novel compounds of hybrid structure pyridazine-coumarin through a multistep approach based on Knoevenagel reaction using as key intermediate pyridazinone 16 as potent, selective, and reversible inhibitors of monoamine oxidase
B (MAO-B). Compounds $9 \mathrm{~b}$ and $9 \mathrm{~d}$ are the most potent compounds with $\mathrm{IC}_{50}$ values of $0.75 \pm 0.17 \mu \mathrm{M}$ and $0.56 \pm 0.04 \mu \mathrm{M}$, respectively, and lack of cytotoxic effects. Liang et al. [72] designed and synthesized a novel series of coumarin-dithiocarbamate hybrids for the treatment of $\mathrm{AD}$. The compound $4 \mathrm{n}$ was found to inhibit AChE ( $\mathrm{IC}_{50} 0.027 \mu \mathrm{M}$ for hAChE) and good inhibition of Ab aggregation (40.19\% at $25 \mu \mathrm{M})$. The compound $(4 \mathrm{n})$ could interact with the catalytic active site and peripheral anionic site of AChE determined by kinetic and molecular modeling studies. However, compound 4n exhibited remarkable bloodbrain barrier permeability, specific metal-chelating property, and low toxicity in SH-SY5Y neuroblastoma cells. Furthermore, compound $4 \mathrm{n}$ could reverse the cognitive dysfunction of scopolamine-induced $\mathrm{AD}$ mice and did not exhibit any acute toxicity in mice at doses up to $1000 \mathrm{mg} / \mathrm{kg}$. Its excellent in vitro and in vivo profiles proclaimed it as a potential lead molecule to treat $\mathrm{AD}$. Xie et al. [73] designed and synthesized novel hybrids by combining N-benzyl pyridinium moiety and coumarin, with $\mathrm{ChE}$ and MAO-B inhibitory activities. Most of the compounds exhibited excellent inhibitory activity for ChE and A $\beta$ (1-42) self-aggregation and selectively inhibition to MAO-B over MAO-A. The compound(7f) showed excellent inhibitory action against hMAO-B, and balanced inhibitory action for ChEs and hMAO-B $(2.32 \mu \mathrm{M}$ for eqBuChE; $1.57 \mu \mathrm{M}$ for hMAO-B; $0.0373 \mu \mathrm{M}$ for eeAChE). The compound $7 \mathrm{f}$ was found to be a mixed-type inhibitor, which interacts simultaneously to CAS and PAS of AChE, determined by molecular modeling and kinetic studies and it was a competitive inhibitor for the active site of MAO-B. Furthermore, compound $7 \mathrm{f}$ with lack of toxicity on PC12 neuroblastoma cells exhibited good ability to inhibit $A \beta$ (1-42) self-aggregation and cross the blood-brain barrier. Kong et al. [74] designed and synthesized a series of coumarin-pargyline hybrids (4a-x) and screened as novel dual inhibitors of AD. Most of the compounds revealed an excellent ability to inhibit amyloid- $\beta(A \beta)$ aggregation and monoamine oxidases. Especially, compound $(\times 4)$ exhibited significant inhibitory actions against monoamine oxidases $\left(\mathrm{IC}_{50}, 3.275 \pm 0.040 \mu \mathrm{M}\right.$ for MAO-A;0.027 $\pm 0.004 \mu \mathrm{M}$ for MAO-B) and A $\beta 1-42$ aggregation $(54.0 \pm 1.1 \%, 25 \mu \mathrm{M})$. Furthermore, compound $(\times 4)$ showed low toxicity estimated by in vitro cell toxicity test and good blood-brain barrier permeability. These results revealed that compound $(\times 4)$ was an effective and an auspicious candidate for Alzheimer's. Khoobi et al. [75] synthesized a novel series of coumarinlipoic acid hybrids through cycloaddition click reaction and evaluated them for the treatment of AD. All the compounds were investigated for their neuroprotective and cholinesterase inhibitory activities. Among them, compound (11) which was found to be the most potent AChE inhibitor, exhibited the excellent inhibitory effect on intracellular ROS formation, and $\beta$-aggregation, as well as the ability of selective biometal chelation and neuroprotection against $\mathrm{H}_{2} \mathrm{O}_{2}$ and $\beta 1$-42-induced cytotoxicity. Collectively, this result indicated that the compound (11) was a promising lead compound with desired multifunctional properties, in the treatment of $\mathrm{AD}$. Baruah et al. [76] evaluated the inhibitory efficacy of two substituted coumarin derivatives on neuroprotective and cholinesterase inhibitory activities in the presence of human SA. The experimental results indicated the inhibition to be of noncompetitive type with both the systems showing substantial inhibitory activity on AChE. The compound chromenyl coumarate was found to be a potent inhibitor $\left(\mathrm{IC}_{50}: 48.49 \pm 5.6 \mathrm{nM}\right.$. These results revealed that the compound was an effective and auspicious candidate for AD. Akbarzadeh et al. [77] designed and synthesized a new series of coumarin-pyridinium hybrids as novel dual inhibitors of AD. The synthesized compounds were evaluated for anti-butyrylcholinesterase and anti-acetylcholinesterase using Ellman's method. Among synthesized derivatives, the compounds (7l) were found to be the most active compound toward AChE (IC $: 10.14$ $\mathrm{mM}), 7 \mathrm{~g}$ and $7 \mathrm{~h}$ exhibited highest $\mathrm{BChE}$ inhibitory activity $\left(\mathrm{IC}_{50}: 0.32\right.$ and $0.43 \mathrm{mM}$, respectively). Among them, the compound $7 \mathrm{~g}$ selectively bound to $\mathrm{BChE}$ with SI of 101.18. The kinetic study of the compounds $7 \mathrm{~g}$ and $7 \mathrm{l}$ revealed that they were mixed type inhibitor for both AChE and BChE. In addition, they showed low inhibitory activity against $\beta$-secretase.

\section{Anticoagulant activity}

Manolov etal. [78] synthesized 4-hydroxycoumarin derivatives. TheX-ray crystallography analysis of 3,3'-(2,3,4-trimethoxyphenylmethylene) bis-(4-hydroxy-2H-1-benzopyran-2-one) (7) and 3,3'-(3,5-imethoxy- 
4-hydroxyphenylmethylene) bis-(4-hydroxy-2H-1-benzopyran-2-one) (9) confirmed the structure of these compounds and a comparative pharmacological study of the anticoagulant effect with respect to warfarin showed that the synthesized compounds have good anticoagulant activities. The most active compound is 3,3'-(4-chlorophenylmethylene) bis-(4-hydroxy-2H-1-benzopyran-2-one) (12) with low toxicity, very good index of absorption and dose-dependent anticoagulant potential (Fig. 17).

\section{Antiparkinsonism activity}

Chimenti et al. [79] synthesized a series of coumarin-3-acyl derivatives and screened for their selective inhibitory potential against monoamine oxidases (Fig. 18). The coumarin-3-carboxylic acids (2a-e) showed selective, reversible inhibitory activity against MAO-B isoform. The compound (2a) exhibited $\mathrm{pIC}_{50} 7.76$, and a selectivity index (pS.I.) 2.94

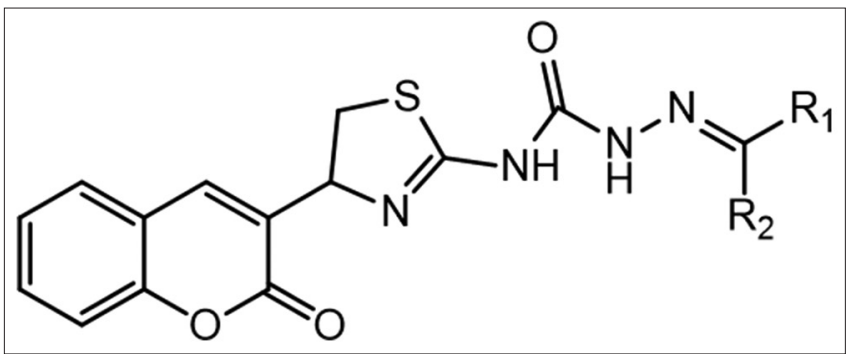

Fig. 20: The structure of heteroaryl semicarbazones synthesized by the reaction of heteroaryl hydrazine carboxamide with aryl aldehydes or ketones

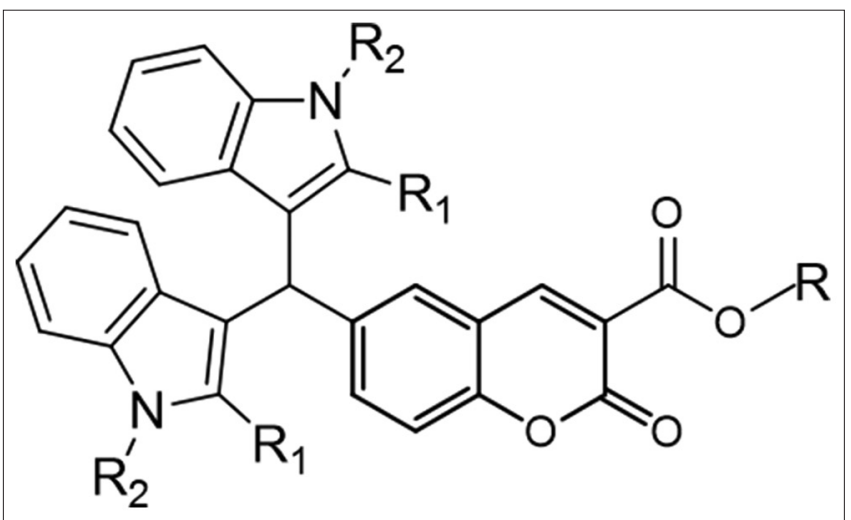

Fig. 21: The structure of a series of novel compounds that have both coumarin and indole entities

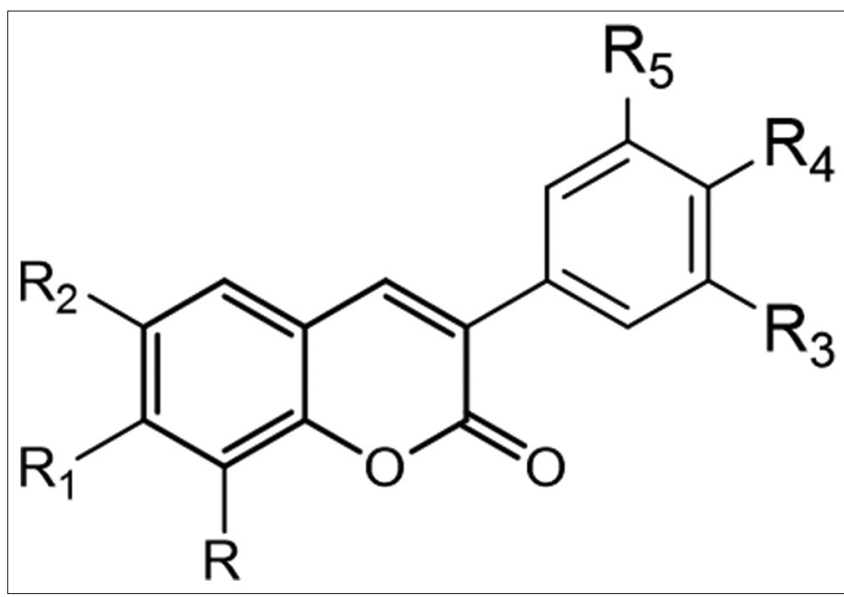

Fig. 22: The structure of coumarin-resveratrol hybrids and the compound ( $2 \mathrm{~b}$ )represented pIC 7.72 and a pS.I. of 2.80. The compounds (3a-e) exhibited high $\mathrm{pIC}_{50}$ values against both MAO-A and MAO-B isoforms; however, compound (3d) represented excellent potential against MAO-B with a pIC $_{50}$ value of 8.00

\section{Antimalarial activity}

Oketch-Rabah et al. [80] isolated a new antiplasmodial coumarin, 5,7-dimethoxy-8-(3'-hydroxy-3'methyl-1'-butene)-coumarin from the roots of Toddalia asiatica (Fig. 19), revealing its traditional use to treat malaria.

Himangini et al. [81] synthesized coumarin-pyrazoline hybrids and investigated them as an anti-malarial agent against chloroquinesensitive (MRC-02) and chloroquine-resistant (RKL-2) strain of Plasmodium falciparum and Plasmodium berghei malaria. The most active antimalarial compound was 3-(1-benzoyl-5-(4-flurophenyl)4,5-dihydro-1 H-pyrazol-3yl)-7-(diethyamino)-2H-chromen-2one ( $\mathrm{IC}_{50}: 4.21 \mathrm{mg} / \mathrm{ml}$ ) and it provided complete protection to the infected mice at $24 \mathrm{mg} / \mathrm{kg}$ for 4 days. Awasthi et al. [82] synthesized 22 coumarin-triazole derivatives by alkylation of 7-hydroxy-4methyl coumarin followed by click chemistry at seventh-position. The synthesized compounds were investigated for antiplasmodial activity against chloroquine sensitive strain of $P$. falciparum (3D7) and compound 9 was found to be the most potent molecule with $\mathrm{IC}_{50}$ value of $0.763 \pm 0.0124 \mu \mathrm{g} / \mathrm{ml}$.

\section{Anticonvulsant activity}

Siddiqui et al. [83] synthesized multiple coumarin derivatives of heteroaryl semicarbazones by the reaction of heteroaryl hydrazine carboxamide with aryl aldehydes or ketones (Fig. 20). The analogs were tested for their anticonvulsant activity employing pentylenetetrazoleinduced seizure, and maximal electroshock seizure tests at 30, 100, and $300 \mathrm{mg} / \mathrm{kg}$ dose levels along with the study of neurotoxicological indications. Three compounds having 3,4-Cl. $\mathrm{C}_{6} \mathrm{H}_{3}, 2-\mathrm{OCH}_{3} . \mathrm{C}_{6} \mathrm{H}_{4}$, and 4-Br. $\mathrm{C}_{6} \mathrm{H}_{4}$ represented highest anticonvulsant activity at a dose of $30 \mathrm{mg} / \mathrm{kg}$, as compared with phenytoin.

\section{Anti-hyperlipidemic activity}

Sashidhara et al. [84] designed and synthesized derivatives bearing both coumarin and indole moieties in a single molecule (Fig. 21) by the Duff reaction on naphthalene-1-ol, which was engaged in a Knoevenagel type reaction with appropriate active methylene compounds and tested them for hypolipidemic activity. These coumarin aldehyde derivatives were further electrophilically substituted with suitable indoles using iodine in acetonitrile to produce coumarin bis-indole analogs. Similarly, another series of coumarin bis-indole analogs were also synthesized starting from 2-sec-butylphenol to synthesize another set of coumarin bis-indole analogs. These derivatives were investigated for hypolipidemic activity in the hyperlipidemic hamster model. In both the series of compounds, as far as coumarin, a pharmacophore is focused, the derivatives bearing substitution at position three plays a key role, and the presence of ethyl ester over methyl is preferred for profound activity. However, it was noticed that unsubstituted indoles have a good activity profile compared to substituted indoles. Among 12 tested compounds, the one bearing $\mathrm{R}=-\mathrm{C}_{2} \mathrm{H}_{5}$ and $\mathrm{R}_{1}=\mathrm{R}_{2}=-\mathrm{H}$ exhibited lower plasma triglyceride levels by $55 \%$, total cholesterol (TC) by $20 \%$, accompanied by an elevation in HDL-C/TC ratio by $42 \%$ in hyperlipidemic rats to a maximum extent than some of the reference statins.

\section{Tyrosinase inhibitor activity}

Fais et al. [85] resynthesized coumarin-resveratrol hybrids by a traditional Perkin reaction carried out in refluxing DMSO between o-hydroxybenzaldehydes (or their methoxy substituted derivatives) and the corresponding aryl acetic acids, using dicyclohexylcarbodiimide as dehydrating agent to investigate the SAR (Fig. 22). Tyrosinase activity assays were accomplished with L-DOPA as substrate with little modifications and activity of mushroom tyrosinase was evaluated by spectrophotometrictechnique. $\mathrm{IC}_{50}$ values represented that these analogs 
exhibited tyrosinase inhibitory activity. 3-(3,4,5-trihydroxyphenyl)-6,8dihydroxycoumarin was the most potent compound ( $\mathrm{IC}_{50}: 0.27 \mathrm{mM}$ ) than umbelliferone $\left(\mathrm{IC}_{50}: 0.42 \mathrm{mM}\right)$. The kinetic studies discovered that the compound resulted in non-competitive inhibition of tyrosinase and the number and position of free hydroxyl groups play a key role in the biological activity.

\section{Antiobesity activity}

Singh et al. [86] synthesized novel coumarin-dihydro quinazolinone analogs and investigated for agonist activity at GPR109a receptor. A compound 10c exhibited robust agonist activity at GPR109a with $\mathrm{EC}_{50}<11 \mathrm{nM}$. The homology model of human GPR109a protein was assayed to explore the binding capacity of the active molecule with the active site of GPR109a. Further, it was discovered that compound 10c resulted in minimization of body weight in diet-induced obese mice model and reduced leptin in blood plasma and total serum cholesterol.

\section{Antidiabetic activity}

Lu et al. [87] synthesized 4flavonoid-coumarin analogs using natural 8-(6"-umbelliferyl)-apigenin as a lead moiety and screened for their $\alpha$-glucosidase inhibitory and glucose consumption promoting activity. The SAR studies revealed that $\mathrm{C} 8 / \mathrm{C} 7-\mathrm{C6}$ " and C6/C5-C6" analogs improved $\alpha$-glucosidase inhibition as compared with their flavone and coumarin lead structures. Compounds (5a) and (14a) were recognized as new $\alpha$-glucosidase and $\alpha$-amylase dual inhibitors similar to acarbose. Furthermore, compounds (5a) and (14a) exhibited glucose consumption-promoting activity in insulin-resistant and non-insulin resistant HepG2 cells models. Therefore, compounds (5a) and (14a) could be potential drug candidates for drug design to treat diabetes mellitus. Saeed et al. [88] designed and synthesized three series of diamine-bridged bis-coumarinyl oxadiazole hybrids by one-pot multicomponent technique. The synthesized conjugates $(4 a-j, 5 a-j$, and $6 \mathrm{a}-\mathrm{j})$ were screened for potential inhibitory activity on $\alpha$-glucosidase enzyme. Compound (6f) was used as the lead molecule that selectively inhibits the $\alpha$-glucosidase enzyme ( $\mathrm{IC}_{50}$ value: $6 \mathrm{f}$ of $0.07 \pm 0.001 \mu \mathrm{M}$ ). This inhibition value was approximately 545 -fold higher compared to the standard drug. Compound $6 \mathrm{f}$ was also appeared as the lead molecule with good inhibition strength $\left(\mathrm{IC}_{50}: 0.04 \pm 0.02 \mu \mathrm{M}\right)$ against intestinal maltase-glucoamylase. Against $\beta$-glucosidase enzyme, compound (6g) was emerged as the lead inhibitor with an $\mathrm{IC}_{50}$ value of $0.08 \pm 0.002 \mu \mathrm{M}$. Michaelis-Menten kinetic experiments were performed to explore the mechanism of inhibition. Molecular docking studies of the synthesized compounds were accomplished against glucosidase enzyme to explore ligand-protein interactions at the molecular level.

\section{CONCLUSION}

Coumarins and its analogs obtained from either natural or synthetic sources exhibited vital biological potential. The key role of coumarin derivatives in plants and animal biology has not been explored until now. The study of novel approaches employed to design and synthesize coumarin analogs bearing essential biological activities along with the study of SAR in addition to the proposed mechanism of action is incorporated in this review. Therefore, this review will help the researchers to design novel coumarin analogs by careful understanding of SAR studies incorporated in this review.

\section{ACKNOWLEDGMENT}

The author is appreciative of Dr. Prasanta K. Mohapatra and Mr. Rajnish Srivastava for their expert advice and inspiration.

\section{AUTHORS' CONTRIBUTIONS}

Mandeep Kumar Gupta initiated the idea of designing the review article and downloaded relevant publications from SciFinder, PubMed, ScienceDirect, and Google Scholar, and Research Gate database. Sachin Chaudhary and Sushil Kumar assisted in designing the manuscript.

\section{CONFLICTS OF INTEREST}

The authors declare that they have no conflicts of interest.

\section{REFERENCES}

1. Sarker SD, Nahar L. Progress in the chemistry of naturally occurring coumarins. Prog Chem Org Nat Prod 2017;106:241-304.

2. Pangal A, Gazge M, Mane V, Shaikh JA. Various pharmacological aspects of couamrin derivatives: A review. Int J Pharm Res Biosci 2013;2:168-94.

3. Rohini K, Srikumar PS. Therapeutic role of coumarins and coumarinrelated compounds. J Thermodyn Catal 2014;5:1-3.

4. Klenkar J, Molnar M. Natural and synthetic coumarins as potential anticancer agents. J Chem Pharm Res 2015;7:1223-38.

5. Constantinou AI, Kamath N, Murley JS. Genistein inactivates bcl-2, delays the G2/M phase of the cell cycle, and induces apoptosis of human breast adenocarcinoma MCF-7 cells. Eur J Cancer 1998;34:1927-34.

6. Egan D, O'Kennedy R, Moran E, Cox D, Prosser E, Thornes RD, et al. The pharmacology, metabolism, analysis, and applications of coumarin and coumarin-related compounds. Drug Metab Rev 1990;22:503-29.

7. Egan DA, O'Kennedy R. Rapid and sensitive determination of coumarin and 7-hydroxycoumarin and its glucuronide conjugate in urine and plasma by high-performance liquid chromatography. J Chromatogr 1992;582:137-43.

8. Finn GJ, Kenealy E, Creaven BS, Egan DA. In vitro cytotoxic potential and mechanism of action of selected coumarins, using human renal cell lines. Cancer Lett 2002; 183:61-8.

9. Lake BG. Coumarin metabolism, toxicity and carcinogenicity: Relevance for human risk assessment. Food Chem Toxicol 1999;37:423-53.

10. Guilet D, Séraphin D, Rondeau D, Richomme P, Bruneton J. Cytotoxic coumarins from calophyllum dispar. Phytochemistry 2001;58:571-5.

11. Murray RDH, Mendez J, Brown SA. Coumarin activity in plants and bio-organism aspects. $2^{\text {nd }}$ ed. John Wiley 1982;45-55.

12. Jamier V, Marut W, Valente S, Chereau C, Chouzenoux S, Nicco C, et al. Chalcone-coumarin derivatives as potential anti-cancer drugs: An in vitro and in vivo investigation. Anticancer Agents Med Chem 2014;14:963-74

13. Chen H, Walsh CT. Coumarin formation in novobiocin biosynthesis: Beta-hydroxylation of the aminoacyl enzyme tyrosyl-S-novH by a cytochrome P450 novI. Chem Biol 2001;8:301-12.

14. von Weymarn LB, Murphy SE. CYP2A13-catalysed coumarin metabolism: Comparison with CYP2A5 and CYP2A6. Xenobiotica 2003;33:73-81.

15. Ritschel WA, Grummich KW, Kaul S, Hardt TJ. Biopharmaceutical parameters of coumarin and 7-hydroxycoumarin. Die Pharma Ind 1981;43:271-6.

16. Stiefel C, Schubert T, Morlock GE. Bioprofiling of cosmetics with focus and streamlined coumarin analysis. ACS Omega 2017;2:5242-50.

17. Dempsey E, O'Sullivan C, Smyth MR, Egan D, O'Kennedy R, Wang J, et al. Development of an antibody-based amperometric biosensor to study the reaction of 7-hydroxycoumarin with its specific antibody. Analyst 1993;118:411-3.

18. Sharma S, Byrne H, O'Kennedy RJ. Antibodies and antibody-derived analytical biosensors. Essays Biochem 2016;60:9-18.

19. Shilling WH, Crampton RF, Longland RC. Metabolism of coumarin in man. Nature 1969;221:664-5.

20. Moran E, O'Kennedy R, Thornes RD. Analysis of coumarin and its urinary metabolites by high-performance liquid chromatography. J Chromatogr 1987;416:165-9.

21. Pelkonen O, Turpeinen M, Uusitalo J, Rautio A, Raunio H. Prediction of drug metabolism and interactions on the basis of in vitro investigations. Basic Clin Pharmacol Toxicol 2005;96:167-75.

22. Bogan DP, Deasy B, O'Kennedy R, Smyth MR, Fuhr U. Determination of free and total 7-hydroxycoumarin in urine and serum by capillary electrophoresis. J Chromatogr B Biomed Appl 1995;663:371-8.

23. Rautio A, Kraul H, Kojo A, Salmela E, Pelkonen O. Interindividual variability of coumarin 7-hydroxylation in healthy volunteers. Pharmacogenetics 1992;2:227-33.

24. Egan DA, O'Kennedy R. Spectrofluorimetric method for the quantification of 7-hydroxycoumarin in urine and plasma using both extracted and unextracted samples. Analyst 1993;118:201-3.

25. Bogan D, Deasy B, O'Kennedy R, Smyth M. The use of capillary electrophoresis for studying interspecies differences in coumarin metabolism in liver microsomes. Xenobiotica 1996;26:437-48.

26. Pelkonen O, Rautio A, Raunio H, Pasanen M. CYP2A6: A human coumarin 7-hydroxylase. Toxicology 2000;144:139-47. 
27. Pelkonen O, Mäenpää J, Taavitsainen P, Rautio A, Raunio H. Inhibition and induction of human cytochrome P450 (CYP) enzymes. Xenobiotica 1998;28:1203-53.

28. Lacy A, O'Kennedy R. Studies on coumarins and coumarin-related compounds to determine their therapeutic role in the treatment of cancer. Curr Pharm Des 2004;10:3797-811.

29. Fentem JH, Fry JR. Metabolism of coumarin by rat, gerbil and human liver microsomes. Xenobiotica 1992;22:357-67.

30. Lin PY, Yeh KS, Su CL, Sheu SY, Chen T, Ou KL, et al. Synthesis and antibacterial activities of novel 4-hydroxy-7-hydroxy- and 3-carboxycoumarin derivatives. Molecules 2012;17:10846-63.

31. Hu Y, Shen Y, Wu X, Tu X, Wang GX. Synthesis and biological evaluation of coumarin derivatives containing imidazole skeleton as potential antibacterial agents. Eur J Med Chem 2018;143:958-69.

32. Amin KM, Abou-Seri SM, Abdelnaby RM, Rateb HS, Khalil MA, Hussein MM. Synthesis and biological evaluation of novel coumarin derivatives as potential antimicrobial agents. Int J Pharm Pharm Sci 2016;8:109-19.

33. Aziem AA. An efficient and simple synthesis of 2, 3-dihydro-1,3,4thiazoles, pyrazoles and coumarin containing benzofuran moiety using both conventional and grinding methods. Int J Pharm Pharm Sci 2015;7:61-8

34. Hamid SJ, Kubba AA. Synthesis and characterization of new coumarin derivatives containing various moieties with antibacterial activities. Int J Pharm Pharm Sci 2015;7:70-4.

35. Tandon R, Ponnan P, Aggarwal N, Pathak R, Baghel AS, Gupta G, et al. Characterization of 7-amino-4-methylcoumarin as an effective antitubercular agent: Structure-activity relationships. J Antimicrob Chemother 2011;66:2543-55.

36. Reddy DS, Kongot M, Netalkar SP, Kurjogi MM, Kumar R, Avecilla F, et al. Synthesis and evaluation of novel coumarin-oxime ethers as potential anti-tubercular agents: Their DNA cleavage ability and BSA interaction study. Eur J Med Chem 2018;150:864-75.

37. Mangasuli SN, Hosamani KM, Devarajegowda HC, Kurjogi MM, Joshi SD. Synthesis of coumarin-theophylline hybrids as a new class of anti-tubercular and anti-microbial agents. Eur J Med Chem 2018;146:747-56.

38. Benci K, Mandić L, Suhina T, Sedić M, Klobučar M, Kraljević Pavelić S, et al. Novel coumarin derivatives containing 1,2,4-triazole, 4,5-dicyanoimidazole and purine moieties: Synthesis and evaluation of their cytostatic activity. Molecules 2012;17:11010-25

39. Cheng JF, Chen M, Wallace D, Tith S, Arrhenius T, Kashiwagi H, et al. Discovery and structure-activity relationship of coumarin derivatives as TNF-alpha inhibitors. Bioorg Med Chem Lett 2004;14:2411-5.

40. Lee S, Sivakumar K, Shin WS, Xie F, Wang Q. Synthesis and antiangiogenesis activity of coumarin derivatives. Bioorg Med Chem Lett 2006; 16:4596-9.

41. Chen W, Tang W, Lou L, Zhao W. Pregnane, coumarin and lupane derivatives and cytotoxic constituents from Helicteres angustifolia. Phytochemistry 2006;67:1041-7.

42. Nofal ZM, El-Zahar MI, El-Karim SS. Novel coumarin derivatives with expected biological activity. Molecules 2000;5:99-113.

43. Lou LL, Zhao P, Cheng ZY, Guo R, Yao GD, Wang XB, et al. A new coumarin from Juglans mandshurica maxim induce apoptosis in hepatocarcinoma cells. Nat Prod Res 2018;1-3. Avaliable from: $10.1080 / 14786419.2018 .1434646$ [Last accessed on 2018 Feb 04].

44. Tan S, He F, Kong T, Wu J, Liu Z. Design, synthesis and tumor cell growth inhibitory activity of 3-nitro-2H-cheromene derivatives as histone deacetylaes inhibitors. Bioorg Med Chem 2017;25:4123-32.

45. Lv N, Sun M, Liu C, Li J. Design and synthesis of 2-phenylpyrimidine coumarin derivatives as anticancer agents. Bioorg Med Chem Lett 2017;27:4578-81.

46. Yu H, Hou Z, Tian Y, Mou Y, Guo C. Design, synthesis, cytotoxicity and mechanism of novel dihydroartemisinin-coumarin hybrids as potential anti-cancer agents. Eur J Med Chem 2018;151:434-49.

47. Batran RZ, Kassem AF, Abbas EMH, Elseginy SA, Mounier MM. Design, synthesis and molecular modeling of new 4-phenylcoumarin derivatives as tubulin polymerization inhibitors targeting MCF-7 breast cancer cells. Bioorg Med Chem 2018;26:3474-90.

48. Ayati A, Bakhshaiesh TO, Moghimi S, Esmaeili R, Majidzadeh-A K, Safavi M, et al. Synthesis and biological evaluation of new coumarins bearing 2,4-diaminothiazole-5-carbonyl moiety. Eur J Med Chem 2018;155:483-91.

49. Singh H, Singh JV, Gupta MK, Saxena AK, Sharma S, Nepali K, et al. Triazole tethered isatin-coumarin based molecular hybrids as novel antitubulin agents: Design, synthesis, biological investigation and docking studies. Bioorg Med Chem Lett 2017;27:3974-9.

50. Guo Y, Wang Y, Li H, Wang K, Wan Q, Li J, et al. Novel nitric oxide donors of phenylsulfonylfuroxan and 3-benzyl coumarin derivatives as potent antitumor agents. ACS Med Chem Lett 2018;9:502-6.

51. Luo G, Li X, Zhang G, Wu C, Tang Z, Liu L, et al. Novel SERMs based on 3-aryl-4-aryloxy-2H-chromen-2-one skeleton - A possible way to dual ER $\alpha$ /VEGFR-2 ligands for treatment of breast cancer. Eur J Med Chem 2017;140:252-73.

52. Bu M, Cao T, Li H, Guo M, Yang BB, Zeng C, et al. Synthesis and biological evaluation of novel steroidal $5 \alpha, 8 \alpha$-epidioxyandrost-6-ene$3 \beta$-ol-17-(O-phenylacetamide)oxime derivatives as potential anticancer agents. Bioorg Med Chem Lett 2017;27:3856-61.

53. Al-Haiza MA, Mostafa MS, El-Kady MY. Synthesis and biological evaluation of some new coumarin derivatives. Molecules 2003;8:275-86.

54. López-Rojas P, Janeczko M, Kubiński K, Amesty Á, Masłyk M, EstévezBraun A, et al. Synthesis and antimicrobial activity of 4-substituted 1,2,3-triazole-coumarin derivatives. Molecules 2018;23:E199.

55. Tiwari SV, Seijas JA, Vazquez-Tato MP, Sarkate AP, Karnik KS, Nikalje APG, et al. Facile synthesis of novel coumarin derivatives, antimicrobial analysis, enzyme assay, docking study, ADMET prediction and toxicity study. Molecules 2017;22:E1172.

56. Kostova I, Raleva S, Genova P, Argirova R. Structure-activity relationships of synthetic coumarins as HIV-1 inhibitors. Bioinorg Chem Appl 2006;2006:68274.

57. Jashari A, Hey-Hawkins E, Mikhova B, Draeger G, Popovski E. An improved synthesis of 4-chlorocoumarin-3-sulfonyl chloride and its reactions with different bidentate nucleophiles to give pyrido[1',2':2,3]- and thiazino[3',2':2,3]-1,2,4-thiadiazino[6,5-c] benzopyran-6-one 7,7-dioxides. Molecules 2007;12:2017-28.

58. Majumdar M. Antioxidant activity and inhibitory potential of few Indian medicinal plants against key hyperglycemic enzymes. Res J Biotechnol 2012;7:186-91.

59. Goudgaon NM, Sheshikant BU, Dhage D. Synthesis and biological activities of 3-\{6-[3-(substitutedphenyl)-1-phenyl-1h-pyrazol-4-yl]2-thioxo-1，2，5，6-tetrahydropyrimidin-4-yl $\}$-2h-chromen-2-ones. Heterolett 2012;2:154-61.

60. Melagraki G, Afantitis A, Igglessi-Markopoulou O, Detsi A, Koufaki M, Kontogiorgis C, et al. Synthesis and evaluation of the antioxidant and anti-inflammatory activity of novel coumarin-3-aminoamides and their alpha-lipoic acid adducts. Eur J Med Chem 2009;44:3020-6

61. Singh TS, Rao BS, Mohan H, Mittal JP. A pulse radiolysis study of coumarin and its derivatives. J Photochem Photobiol Chem 2002; $153: 163-71$.

62. Beillerot A, Domínguez JC, Kirsch G, Bagrel D. Synthesis and protective effects of coumarin derivatives against oxidative stress induced by doxorubicin. Bioorg Med Chem Lett 2008;18:1102-5.

63. Nicolaides DN, Gautam DR, Litinas KE, Hadjipavlou-Litina DJ, Fylaktakidou KC. Synthesis and evaluation of the antioxidant and antiinflammatory activities of some benzo[1]khellactone derivatives and analogues. Eur J Med Chem 2004;39:323-32.

64. Sreeja S, Mathan S, Kumaran J. Design, Synthesis and pharmacological evaluation of new coumarin derivatives. Int J Adv PharmBiol Sci 2012;2:80-91

65. Gummudavelly S, Ranganath YS, Bhasker S, Rajkumar N. Synthesis and biological screening of some novel coumarin derivatives. Asian J Res Chem 2009;2:46-8.

66. Kontogiorgis CA, Hadjipavlou-Litina DJ. Synthesis and biological evaluation of novel coumarin derivatives with a 7-azomethine linkage. Bioorg Med Chem Lett 2004;14:611-4

67. Chen LZ, Sun WW, Bo L, Wang JQ, Xiu C, Tang WJ, et al. New arylpyrazoline-coumarins: Synthesis and anti-inflammatory activity. Eur J Med Chem 2017;138:170-81

68. Liu BY, Zhang C, Zeng KW, Li J, Guo XY, Zhao MB, et al. Antiinflammatory prenylated phenylpropenols and coumarin derivatives from Murraya exotica. J Nat Prod 2018;81:22-33.

69. Keri RS, Hosamani KM, Shingalapur RV, Hugar MH. Analgesic, antipyretic and DNA cleavage studies of novel pyrimidine derivatives of coumarin moiety. Eur J Med Chem 2010;45:2597-605.

70. Zhou X, Wang XB, Wang T, Kong LY. Design, synthesis, and acetylcholinesterase inhibitory activity of novel coumarin analogues. Bioorg Med Chem 2008;16:8011-21.

71. Costas-Lago MC, Besada P, Rodríguez-Enríquez F, Viña D, Vilar S, Uriarte E, et al. Synthesis and structure-activity relationship study of novel 3-heteroarylcoumarins based on pyridazine scaffold as selective MAO-B inhibitors. Eur J Med Chem 2017;139:1-1.

72. Jiang N, Huang Q, Liu J, Liang N, Li Q, Li Q, et al. Design, synthesis and biological evaluation of new coumarin-dithiocarbamate hybrids as multifunctional agents for the treatment of Alzheimer's disease. Eur J Med Chem 2018;146:287-98. 
73. Lan JS, Ding Y, Liu Y, Kang P, Hou JW, Zhang XY, et al. Design, synthesis and biological evaluation of novel coumarin-N-benzyl pyridinium hybrids as multi-target agents for the treatment of Alzheimer's disease. Eur J Med Chem 2017;139:48-59.

74. Yang HL, Cai P, Liu QH, Yang XL, Li F, Wang J, et al. Design, synthesis and evaluation of coumarin-pargyline hybrids as novel dual inhibitors of monoamine oxidases and amyloid- $\beta$ aggregation for the treatment of Alzheimer's disease. Eur J Med Chem 2017;138:715-28.

75. Jalili-Baleh L, Forootanfar H, Küçükkılınc TT, Nadri H, Abdolahi Z, Ameri A, et al. Design, synthesis and evaluation of novel multi-targetdirected ligands for treatment of alzheimer's disease based on coumarin and lipoic acid scaffolds. Eur J Med Chem 2018;152:600-14.

76. Baruah P, Basumatary G, Yesylevskyy SO, Aguan K, Bez G, Mitra S, et al. Novel coumarin derivatives as potent acetylcholinesterase inhibitors: Insight into efficacy, mode and site of inhibition. J Biomol Struct Dyn 2018;1-6. Avaliable from: 10.1080/07391102.2018.1465853. [Last accessed on 2018 May 04].

77. Vafadarnejad F, Mahdavi M, Karimpour-Razkenari E, Edraki N, Sameem B, Khanavi M, et al. Design and synthesis of novel coumarinpyridinium hybrids: In vitro cholinesterase inhibitory activity. Bioorg Chem 2018;77:311-9.

78. Manolov I, Maichle-Moessmer C, Danchev N. Synthesis, structure, toxicological and pharmacological investigations of 4-hydroxycoumarin derivatives. Eur J Med Chem 2006;41:882-90.

79. Chimenti F, Secci D, Bolasco A, Chimenti P, Granese A, Befani O, et al. Inhibition of monoamine oxidases by coumarin-3-acyl derivatives: Biological activity and computational study. Bioorg Med Chem Lett 2004; 14:3697-703.

80. Oketch-Rabah HA, Mwangi JW, Lisgarten J, Mberu EK. A new antiplasmodial coumarin from Toddalia asiatica roots. Fitoterapia 2000;71:636-40

81. Himangini, Pathak DP, Sharma V, Kumar S. Designing novel inhibitors against falcipain-2 of Plasmodium falciparum. Bioorg Med Chem Lett 2018;28:1566-9

82. Yadav N, Agarwal D, Kumar S, Dixit AK, Gupta RD, Awasthi SK, et al. In vitro antiplasmodial efficacy of synthetic coumarin-triazole analogs. Eur J Med Chem 2018;145:735-45.

83. Siddiqui N, Arshad MF, Khan SA. Synthesis of some new coumarin incorporated thiazolyl semicarbazones as anticonvulsants. Acta Pol Pharm 2009;66:161-7.

84. Sashidhara KV, Kumar A, Kumar M, Srivastava A, Puri A. Synthesis and antihyperlipidemic activity of novel coumarin bisindole derivatives. Bioorg Med Chem Lett 2010;20:6504-7.

85. Fais A, Corda M, Era B, Fadda MB, Matos MJ, Quezada E, et al. Tyrosinase inhibitor activity of coumarin-resveratrol hybrids. Molecules 2009;14:2514-20.

86. Singh LR, Kumar A, Upadhyay A, Gupta S, Palanati GR, Sikka K, et al. Discovery of coumarin-dihydroquinazolinone analogs as niacin receptor 1 agonist with in vivo anti-obesity efficacy. Eur J Med Chem 2018;152:208-22.

87. Sun H, Song X, Tao Y, Li M, Yang K, Zheng H, et al. Synthesis \&amp; $\alpha$-glucosidase inhibitory and glucose consumption-promoting activities of flavonoid-coumarin hybrids. Future Med Chem 2018;10:1055-66.

88. Kazmi M, Zaib S, Ibrar A, Amjad ST, Shafique Z, Mehsud S, et al. A new entry into the portfolio of $\alpha$-glucosidase inhibitors as potent therapeutics for Type 2 diabetes: Design, bioevaluation and one-pot multi-component synthesis of diamine-bridged coumarinyl oxadiazole conjugates. Bioorg Chem 2018;77:190-202. 